Available online on 15.12.2019 at http://jddtonline.info
Open Access to Pharmaceutical and Medical Research
unrestricted non-commercial use, provided the original work is properly cited

Open? Access

Research Article

\title{
Estimation of D-dimer Level among Sudanese Women under Contraceptive Pill
}

\author{
Zeinab Atif Ahmed Osman1, Sara Elsadig Babiker ${ }^{3}$, Nihad Elsadig Babiker ${ }^{1,2 *}$ \\ 1 Faculty of Medical Laboratory Sciences, National University, Sudan \\ 2 Darfur University College, Sudan \\ ${ }^{3}$ MRCOG, Sultan Qaboose Hospital, Slalah, Oman
}

\begin{abstract}
Contraceptives are intentional prevention of conception through the use of various devices sexual practices, chemicals, drugs or surgical procedures become a contraceptive if its purpose is to prevent a woman from becoming pregnant. This is a cross sectional study conducted at ALnow Hospital Khartoum, Sudan, the study aimed to estimate D.dimer levels among Sudanese women take contraceptive pill. 50 Women uses contraceptive pill used as a cases and 50 apparently health women were used as a control. Three ml of venous blood samples were collected from each subject in 3.8\% tri-sodium citrate (9:1 vol/vol) for D-dimer analysis. The study revealed that was clearly significant increase in D.dimer in women take oral contraceptive pill (p.value 0.000), also the study concluded that D-dimer level was increased in users oral contraceptive Sudanese women, that is increase the coagubility of the blood and might be become as a risk factor.
\end{abstract}

Keywords: Contraceptive pills, D.dimer, coagubility.

Article Info: Received 07 Oct 2019; $\quad$ Review Completed 18 Nov 2019; $\quad$ Accepted 23 Nov 2019; Available online 15 Dec 2019

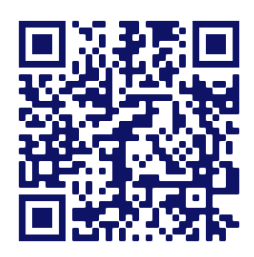

Cite this article as:

Osman ZAA, Babiker SE, Babiker NE, Estimation of D-dimer Level among Sudanese Women under Contraceptive Pill, Journal of Drug Delivery and Therapeutics. 2019; 9(6-s):53-57 http://dx.doi.org/10.22270/jddt.v9i6-s.3738

*Address for Correspondence:

Nihad Elsadig Babiker, Faculty of Medical Laboratory Sciences, National University, Sudan

\section{INTRODUCTION}

Contraceptives are intentional prevention of conception through the use of various devices sexual practices, chemicals, drugs or surgical procedures become a contraceptive if its purpose is to prevent a woman from becoming pregnant [1].

The contraceptives pills are the common name for oral contraception, it's one of the safest, most effective and popular methods of birth control. The pill is made up of synthetic forms of hormones that naturally occur in a female's body progesterone and estrogen, it is works by stopping the action of the hormones that trigger ovulation and preventing the release of an egg; it also thickens the cervical mucus, so it makes it hard for sperm to swim. [1]

There are two kinds of oral contraceptives; combined oral contraceptives (COCs), which contain an estrogen and progestin. Progestin only contraceptives (POPs), which contain a progestin with no estrogen. Combined oral contraceptives are obtainable in 2 basic formulations; the monophasic formulation; in which each active pill contains the same doses of estrogen and progestin, the multiphasic formulations; have different amounts of estrogen or progestin in the active pills.
There are multiple different types of combined oral contraceptive pill use that are options; 28-day cycling; most pill packs have 21 active hormone pills and 7 inactive (placebo) pills. Shortened pill free interval starting the new pack of pills on the first day of menstruation usually decreases the pill-free interval thus allowing less time for a new follicle to develop. Pill-free interval should not be more than 7 days. Extended regimens; there is no biological reason to have monthly with drawal bleeding on oral contraception. There are multiple extended regimens and there are some pills that are formulated and packaged specifically for this type of extended regimen. If a client chooses an extended regimen, a monophasic, combined oral contraceptives must be used.[2]

\section{Advantages and Disadvantages of contraceptives pills:}

Combined oral contraceptives (COCs) benefits; effectiveness, safety in years of consecutive use without risk of complications, ease of reversibility, positive menstrual effects such as; decreased cramps, decreased blood loss and reduction of premenstrual symptoms.

Combined oral contraceptives (COCs) disadvantages; must be taken daily, expensive provide no protection against sexually transmitted infections including HIV, have Possible side effects including; missed periods, breakthrough bleeding, nausea, vomiting, headaches depression and 
decreased libido.

Progestin-only contraceptive pill (POCs) benefits; estrogenfree and therefore; useful for clients unable to tolerate the estrogen effects of combined oral contraceptives or who have contraindications against taking an estrogen containing contraceptive, can be taken during lactation and appears to have no harmful effect on blood pressure or on coagulation. Progestin contraceptive POCs) disadvantages pills; only irregular menstruation.

The combined oral contraceptives have Serious side effects such as; sharp chest pain, coughing up blood, or sudden shortness of breath, pain in calf or leg, crushing chest pain or tightness in the chest, sudden severe headache or vomiting, dizziness or fainting, disturbances of vision or speech, weakness or numbness in an arm or leg, sudden partial or complete loss of vision, breast masses suspicious for potential malignancy, severe abdominal pain or tenderness, severe problems with sleeping, weakness, lack of energy, fatigue, or change in mood, Jaundice and swelling of the fingers or ankles. Also it has a Possible health risks such as; high blood pressure, thrombophlebitis and venous thrombosis with or without embolism arterial thromboembolism, pulmonary embolism, myocardial infarction, cerebral hemorrhage Cerebral thrombosis, gall bladder disease, hepatic adenoma and cigarette smoking increases the risk of serious cardiovascular side effects from hormonal contraceptive use. [3]

\section{D- dimer:}

Is a fibrin degradation product (or FDP), a small protein fragment present in the blood after a blood clot is degraded by fibrinolysis [4]. Values of estimation D-dimer is estimation of quantitative D- dimer level has many diagnostic and prognostic values such as; diagnosis of venous thromboembolism (VTE), identification of individuals at increased risk of first thrombotic event (both arterial and venous), identification of individuals at increased risk of recurrent VTE establishment of the optimal duration of secondary prophylaxis after a first episode of VTE pregnancy monitoring and diagnosis monitoring of disseminated intravascular coagulation

Since the 1960s oral contraceptives have been a well-known risk factor for thromboembolic episodes. Studies indicate that in women taking contraceptives the risk of venous thrombosis increases by 3-6 times [5]. The most common reason for the discontinuation of contraception by women is the occurrence or fear of adverse effects; the most severe ones are thromboembolic Complications that may be a direct cause of death. The oral contraceptive is most widely uses in Sudan, for that is most important to do research in this area to increase the awareness of Sudanese women about the complication of these contraceptives.

\section{MATERIALS \& METHODS}

This was a cross sectional study, conducted at the ALnow Hospital, Khartoum, Sudan during the period May 2019 to July 2019. 50 Sudanese women uses contraceptive pill used as a cases and 50 apparently health women were used as a control. The data was collected using pre-designed structural questionnaire, the demographic, clinical data and the laboratory data included the D-dimer concerning each participant were obtained. The study was approved by the ethical committee of the AL now hospital. Three ml of venous blood were collected in 3.8\% tri-sodium citrate (9:1 vol/vol) for D-dimer analysis, blood samples were centrifuged for 5 minutes at $2500 \mathrm{rpm}$, then the plasma was separated and stored at $-20^{\circ} \mathrm{C}$ until analyzed.

\section{Test procedure}

Firstly Samples were thawed by placing in a water bath for $15-20$ minutes at $37^{\circ} \mathrm{C} .10 \mu \mathrm{L}$ of sample was transfer using pipette to a tube containing the detection buffer and closed the lid of the detection buffer tube, then was mixed the sample thoroughly by shaking it about 10 times. (The sample mixture must be used immediately.). $75 \mu \mathrm{L}$ of a sample mixture was pipette and dispensed into the sample well on the cartridge. Then the sample-loaded cartridge was incubated at room temperature for 12 minutes. To scan the sample-loaded cartridge, was inserted into the cartridge holder of the Instrument for ichroma ${ }^{\mathrm{TM}}$ tests (Ensure proper orientation of the cartridge before pushing it all the way inside the cartridge holder). The test result was read on the display screen of the Instrument for ichroma ${ }^{\mathrm{TM}}$ tests.

\section{RESULTS}

In the present study 50 of contraceptive women were included. Equal percentage presented among case population that age group less than 30 years and more than 30 years (50\%) respectively. In addition, 50 of apparently healthy women were selected as control group, (82\%) their age group less than 30 years and (9\%) more than 30 years (fig 1) (Table 1).

Other data of the research revealed that; the frequency of the woke women among the case group about (28\%) most of them had not a work (72\%) (Table 2) (fig2). Regarding the type of contraceptive were used; More than half of them (54\%) had used (levonogesteral and ethinyle estradiol tablets) Familia contraceptive and (46\%) had used (ethinylestadiol and desogestrel ) Marvelon (table3) (fig3). Majority of them used contraceptive for less than 2 years $(62 \%)$ and (38\%) were used from 2-7 years (table4) (fig4), also about $(76 \%)$ had less than three children while few of them had more than 3 children (24\%) (table5) (fig5). (86\%) hadn't a history of abortion, (12\%) had one abortion and $(2 \%)$ had two times abortion (table6) (fig6). (96\%) hadn't thrombosis, while $4 \%$ had thrombosis (table7) (fig7). For the chronic diseases most of them $(80 \%)$ were normal, $(10 \%)$ had Diabetes mellitus, $(8 \%)$ had hypertension and (2\%) had cardiac aorta (table8) (fig8).

Table (1): Frequency of age group in case and control

\begin{tabular}{|c|c|c|}
\hline \multirow{2}{*}{$\begin{array}{c}\text { Study } \\
\text { Population }\end{array}$} & \multicolumn{2}{|c|}{ Age group } \\
\cline { 2 - 3 } & Less than 30 years & More than 30 years \\
\hline Case & $25(50 \%)$ & $25(50 \%)$ \\
\hline Control & $41(82 \%)$ & $9(18 \%)$ \\
\hline
\end{tabular}

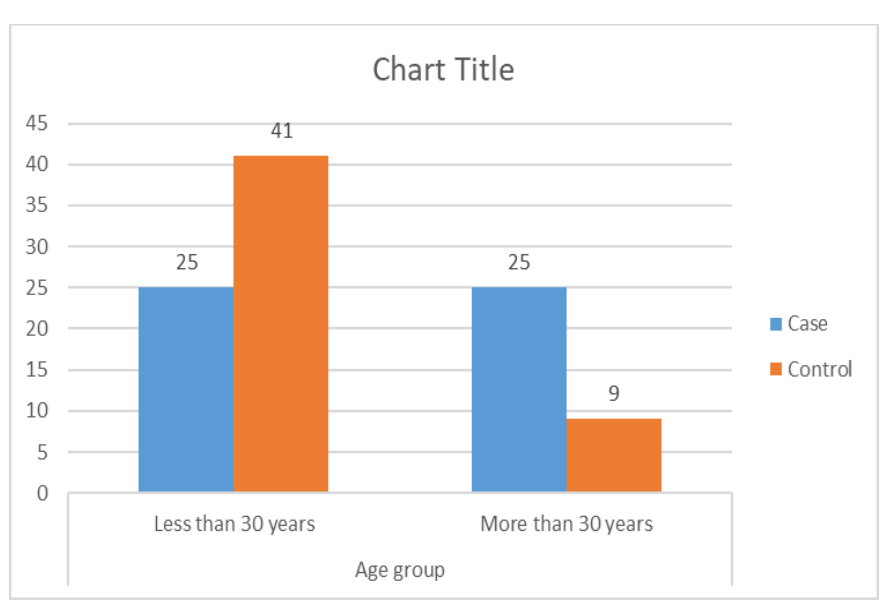

Fig (1): age group among study population CODEN (USA): JDDTAO 


\section{The D-dimer result}

When compared the D- dimer between cases and control there was a significant results $(\mathrm{P}=0.000)$ (table 9).

When the D.dimer correlated with age, types of contraceptives, duration of contraceptive numbers of deliveries, abortion, thrombosis and other disease among case population there was only one significant result in the duration of contraceptive pill taken $(\mathrm{P}=0.000)$ (table10)

Table (2): Frequency of work women among case population

\begin{tabular}{|c|c|c|}
\hline Work & Frequency & Percent \\
\hline Yes & 14 & 28 \\
\hline No & 36 & 72 \\
\hline Total & 50 & 100 \\
\hline
\end{tabular}

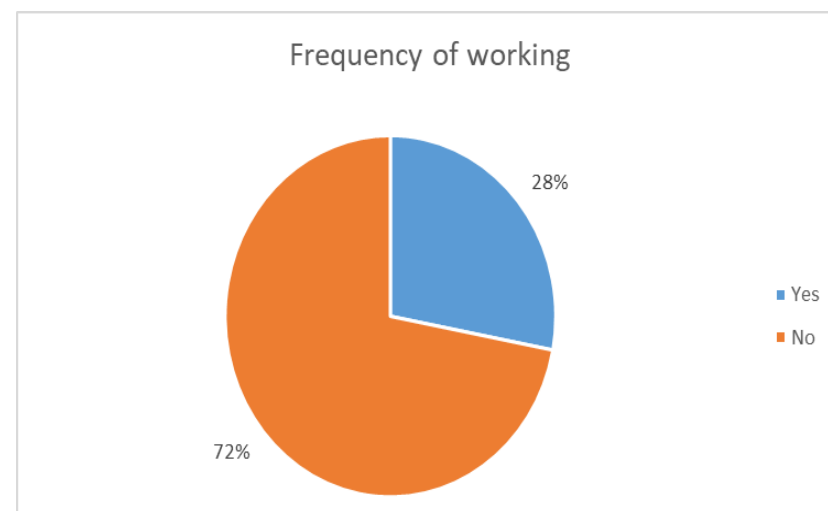

Fig (2): Frequency of work women

Table (3): Types of contraceptive among case population

\begin{tabular}{|c|c|c|}
\hline Type of Contraceptives & Frequency & Percent \\
\hline Familia & 27 & 54 \\
\hline Marvelon & 23 & 46 \\
\hline Total & 50 & 100 \\
\hline
\end{tabular}

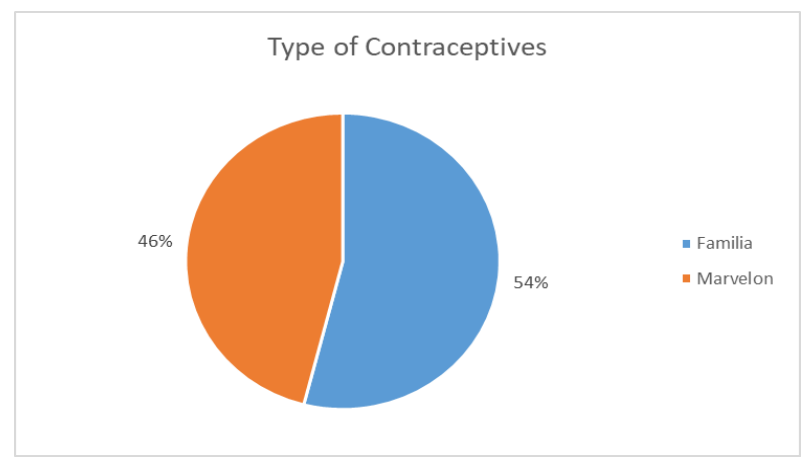

Fig (3): Types of contraceptives
Table (4): Duration of contraceptive among case population

\begin{tabular}{|c|c|c|}
\hline Duration of contraceptive & Frequency & Percent \\
\hline 7month-2 years & 31 & 62 \\
\hline 2-7 years & 19 & 38 \\
\hline Total & 50 & 100 \\
\hline
\end{tabular}

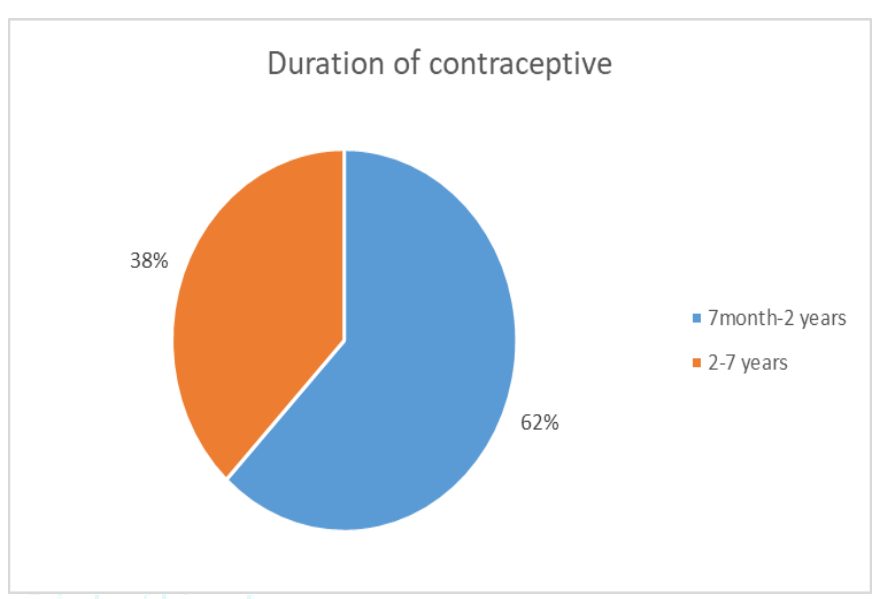

Fig (4): Duration of contraceptive

Table (5): Number of deliveries among case population

\begin{tabular}{|c|c|c|}
\hline Number of deliveries & Frequency & Percent \\
\hline Less than 3 children & 38 & 76 \\
\hline More than 3 children & 12 & 24 \\
\hline Total & 50 & 100 \\
\hline
\end{tabular}

Number of deliveries

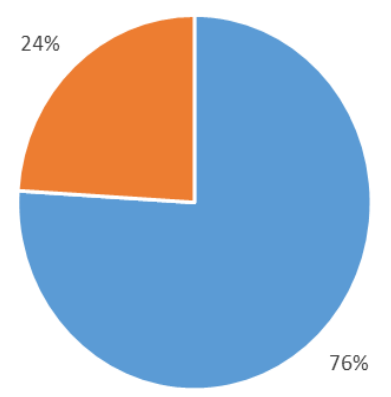

- Less than 3 children

- More than 3 children

Fig (5): Number of deliveries among case population

Table (6): Number of abortions among case population

\begin{tabular}{|c|c|c|}
\hline Times of Abortion & Frequency & Percent \\
\hline $\mathbf{1}$ & 6 & 12 \\
\hline $\mathbf{2}$ & 1 & 2 \\
\hline No & 43 & 86 \\
\hline Total & 50 & 100 \\
\hline
\end{tabular}

CODEN (USA): JDDTAO 


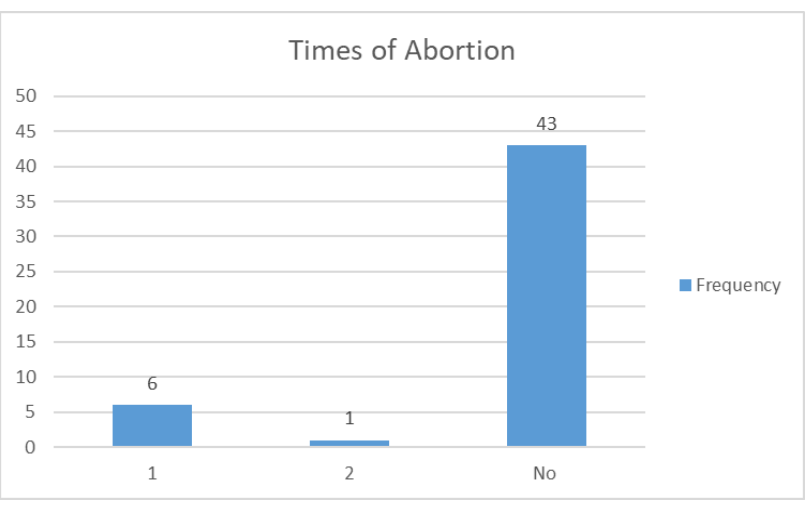

Fig (6): Times of abortion

Table (7): Thrombosis among case population

\begin{tabular}{|c|c|c|}
\hline Thrombosis & Frequency & Percent \\
\hline Yes & 2 & 4 \\
\hline No & 48 & 96 \\
\hline Total & 50 & 100 \\
\hline
\end{tabular}

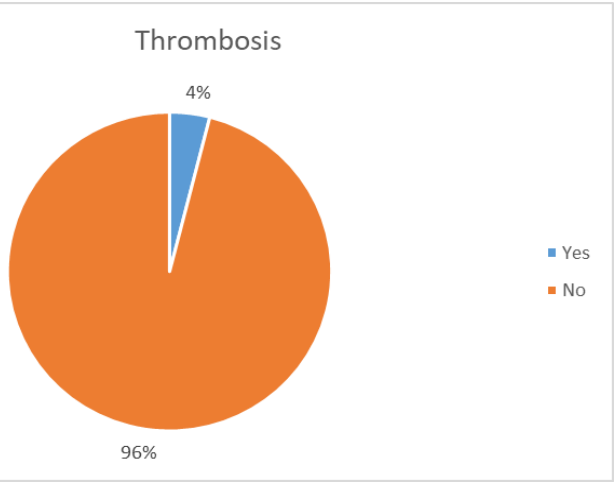

Fig (7): Thrombosis among case population

Table (8): Other disease among case population

\begin{tabular}{|c|c|c|}
\hline Diseases & Frequency & Percent \\
\hline D.M & 5 & 10 \\
\hline Hypertension & 4 & 8 \\
\hline Cardiac Aorta & 1 & 2 \\
\hline No & 40 & 80 \\
\hline Total & 50 & 100 \\
\hline
\end{tabular}

other disease

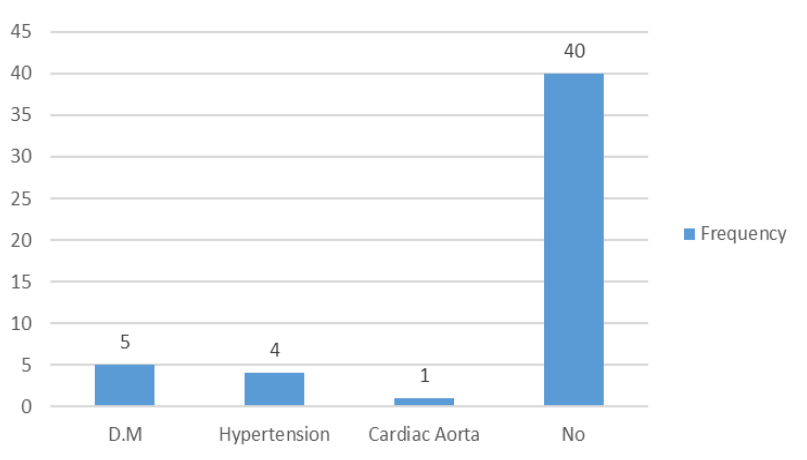

Fig (8): Other disease among case population
Table (9): Mean and STD of D. dimer among study population

\begin{tabular}{|c|c|c|c|}
\hline Parameters & $\begin{array}{c}\text { Case } \\
\text { (mean } \pm \text { Std) }\end{array}$ & $\begin{array}{c}\text { Control } \\
\text { (mean } \pm \text { Std) }\end{array}$ & $\begin{array}{c}\text { P. } \\
\text { value }\end{array}$ \\
\hline D. dimer result & $0.35 \pm 0.07$ & $0.21 \pm 0.07$ & 0.000 \\
\hline
\end{tabular}

Table (10): comparison of D.dimer with age, type of contraceptive, delivery, no of deliveries, abortion, duration of contraceptive, thrombosis and other disease among case population

\begin{tabular}{|l|l|}
\hline Variables & p.value \\
\hline Age & 0.52 \\
\hline Type of contraceptive & 0.26 \\
\hline Delivery & 0.24 \\
\hline number of delivery & 0.13 \\
\hline Abortion & 0.31 \\
\hline Duration & 0.000 \\
\hline Thrombosis & 0.78 \\
\hline Other disease & 0.23 \\
\hline
\end{tabular}

\section{DISCUSSION:}

This is across sectional study conducted in women at Khartoum state from $1 / 7 / 2019$ to $10 / 9 / 2019$ to asses Ddimer level in contraceptive pill and the result compared with normal healthy women as a control. The collected data were analyzed by statistical package of social science (SPSS) program, this research revealed the following results; the frequency of Age group; in case group 25(50\%) less than 30 years and $25(50 \%)$ more than 30 years, for control group; $41(82 \%)$ less than 30 years and $9(18 \%)$ more than 30 years. Contraceptive pill has been available in pharmacies for more than 50 years. Owing to its high effectiveness, full reversibility of its effects and high acceptability by women, it has become the most universal contraceptive method Currently, it is estimated that approx. 100 million women take the contraceptive pill [5].

In the present study there was a significant difference in D. dimer result in case group (mean 0.35, Std \pm 0.07 ) when compared with control group (mean $0.21 \pm$, Std 0.07 Std) (p.value 0.000) that is consistent with other study which reported; significant positive D-dimer in users women than nonusers contraceptives pill [6]. Also Meijers et al said; that was a significant increase of D-dimer during the use of the pills. [7]

In this study the frequency of contraceptive according to their types; famila contraceptive (contain two hormones; progestin and an estrogen) (Frequency 27) (54\%) and marvelon contraceptive (contain two hormones; progestogen and an estrogen) (Frequency 23) (46\%), the two types are more popular used in Sudan. when they were correlated with D- dimer in the case group there was insignificant result with $(p \geq 0.05)$. One of the studies revealed that; there are great differences between individual progesterone components used in contraceptives and that the final effect of a progesterone component depends on the type and dose of the combined oestrogen. It has been shown 
that oral contraceptives influence the level of almost every protein of the blood coagulation system[8]. Also Vliet et al showed that; a greater oestrogen level in hormonal contraceptives contributes to an increased level of sex hormone-binding proteins (SHBPs). The impact of contraceptives on the increased level of SHBPs may be a risk indicator for a thromboembolic event [9]

The frequency of contraceptive duration was taken by the women; less than 2 years (Frequency 31 ) (62\%) and 2-7 years (frequency 19) (38\%) . when the D-dimer correlated with the duration there was a significant result (p.value $0.000)$, that is agree with other study which reported; Ddimer levels increased gradually during a single cycle of oral contraceptive use at least as much as the increases reported after 3 and 6 cycles of oral contraceptive [10]. Also Van et al said; the risk of venous thrombosis was clearly highest during the first three months of use. After one year, the risk of venous thrombosis for oral contraceptive compared with non-users decreased to the overall estimate of a fivefold increased risk [11]. Another study observed the increase of D-dimer level occurring after 3 months of pills use [12]

In addition to that; the frequency of the number of abortions among case population in one abortion (frequency 6) (12\%) and frequency of two time abortion (frequency 1) (2\%) and Majority of them hadn't a history of abortion (frequency 43) (86\%). Also, the frequency of the thrombosis among case population with thrombosis (frequency 2) (4\%) the reminder frequency without thrombosis (frequency 48) (96\%). when they were correlated with D- dimer in the case group there was insignificant result with $(p \geq 0.05)$. As shown in the available publications, oral contraceptives increase the risk of thromboembolic episodes manifesting as an ischemic stroke or myocardial infarction, while the main factor responsible for the formation of thrombi is the oestrogen component level in the pill. Another publications have been describing an oestrogen/progesterone complex increasing the risk of thrombi and embolisms [13]. Tanis et al emphasise the increased risk of arterial thrombosis induced by oral contraceptive use is more pronounced in smokers and women with hypertension, diabetes or hypercholesterolemia [14].

Finally; the D- dimer correlated with other diseases (diabetes mellitus, hypertention and cardiac aorta) in the case group the result was insignificant with $(p \geq 0.05)$. While the frequency of the disease among case group: diabetes mellitus $10 \%$, hypertension $8 \%$ and Cardiac Aorta $2 \%$. The literature confirm that the oral contraceptive pills have many side effect like; thromboembolic disorders, diabetes mellitus complicated by vascular disease severe hypertension and valvular heart disease with complications [15].

\section{CONCLUSION}

D-dimer level was significantly increased in users oral contraceptive sundaes women, that is increase the hypercoagubility of the blood and might be become as a risk factor.

Indeed it most important to implement education program in Sudan by the family medicine in the hospitals, health center and the clinics about the contraceptive to increase the women awareness for how to select the suitable type of contraceptive according to their health status, the effectiveness of contraceptive, the side effect of contraceptive and the most important things is a follow up in 1-3 months for evaluation for oral contraception continuation.

\section{REFERENCES}

1- Mcevoy G K. AHFS Drug Information. Bethesda, MD: American Society of Health systems Pharmacists 2004.

2- $\quad$ DHMH/FHA/CMCH Maryland Family Planning \& Reproductive Health Program Clinical Guidelines Oral Contraceptive Methods - Revised 4/15/2012 Page 1 of 15.

3- Archer DF, Bigrigg A, Smallwood GH, et al. Transdermal delivery of combined hormonal contraception. Dovepress 2004; 69(3):189-195

4- Roger S. Riley, Andrea R. Gilbert, Justin B. Dalton, Sheela Pai, Richard A, McPherson. Widely Used Types and Clinical Applications of D-Dimer Assay, Laboratory Medicine 2016; 47(2):90-102.

5- Joanna Urbaniak, Hanna Zielin'ska-Bliz'niewska, Jarosław Miłon’ski, Piotr Pietkiewicz, Krzysztof Kus'mierczyk, Jurek Olszewski. Effects of oral contraceptives on selected parameters of the homeostatic control system in young women having a sudden disorder of the auditory and/or balance system. Eur Arch Otorh 2015; 272:321-326.

6- Husaynee AJ, Kashmoola MA. Effect of combined oral contraceptive pills on some haemostatic parameters. Ann. Coll. Med. Mousl 2007; 33(1\&2): 66-69.

7- Meijers JC, Middeldorp S, Tekelenburg W, van den Ende AE, Tans G, Prins MH et al. Increased fibrinolytic activity during use of oral contraceptives is counteracted by an enhanced factor XI-independent down regulation of fibrinolysis. a randomized cross-over study of two low-dose oral contraceptives. Thromb Haemost. 2000; 84(1):9-14.

8- Sitruk-Ware R. New progestagens for contraceptive use. Hum Reprod Update 2006; 12(2):169-178.

9- Van Vliet HA, Frolich M, Christella $M$ et al. Association between sex hormone-binding globulin levels and activated protein $\mathrm{C}$ resistance in explaining the risk of thrombosis in users of oral contraceptives containing different progestogens. Hum Reprod 2005; 20(2):563-568.

10- Carolyn L. Westhoff AB, Andrew Eisenberger c, Rosalind Tanga, Serge Cremers d,Lisa V. Grossmanb, Malcolm C. Pikee. Clotting factor changes during the first cycle of oral contraceptive use. Contraception 2016; (93):70-76

11- van Hylckama Vlieg A, Helmerhorst FM, Vandenbroucke JP, Doggen CJ, Rosendaal FR. The venous thrombotic risk of oral contraceptives, effects of oestrogen dose and progestogen type: results of the MEGA case-control study. BMJ 2009; 339:b2921.

12- klipping C, Duijkers I, Parke S, Mellinger U, Serrani M, Junge W. Hemostatic effects of a novel estradiol-based oral contraceptive, an open-label, randomized, crossover study of estradiol valerate/dienogest versus ethinylestradiol/ levonorgestrel. Drugs R D 2011; 11(2):159-170.

13- Tchaikovski SN, Rosing J. Mechanisms of estrogeninduced venous thromboembolism. Thromb Res 2010; 126(1):5-11.

14- Tanis BC, Rosendaal FR, Venous and arterial thrombosis during oral contraceptive use: risks and risk factors. Semin Vasc Med 2003; 3(1):69-84.

15- Dhmh Fha Cmch. Maryland Family Planning \& Reproductive Health Program Clinical Guidelines Oral Contraceptive Methods 2012; 1-15. 